\title{
Assessing and simulation of membrane technology for modifying starchy wastewater treatment
}

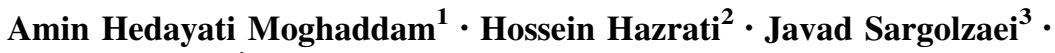 \\ Jalal Shayegan $^{4}$
}

Received: 7 November 2015/Accepted: 15 November 2016/Published online: 28 November 2016

(c) The Author(s) 2016. This article is published with open access at Springerlink.com

\begin{abstract}
In this study, a hydrophilic polyethersulfone membrane was used to modify the expensive and low efficient conventional treatment method of wheat starch production that would result in a cleaner starch production process. To achieve a cleaner production, the efficiency of starch production was enhanced and the organic loading rate of wastewater that was discharged into treatment system was decreased, simultaneously. To investigate the membrane performance, the dependency of rejection factor and permeate flux on operative parameters such as temperature, flow rate, concentration, and $\mathrm{pH}$ of feed were studied. Response surface methodology (RSM) has been applied to arrange the experimental layout which reduced the number of experiments and also the interactions between the parameters were considered. The maximum achieved rejection factor and permeate flux were 97.5\% and $2.42 \mathrm{~L} \mathrm{~min}^{-1} \mathrm{~m}^{-2}$, respectively. Furthermore, a fuzzy inference system was selected to model the nonlinear relations between input and output variable which cannot easily explained by physical models. The best agreement between the experimental and predicted data for permeate flux was denoted by correlation coefficient
\end{abstract}

Amin Hedayati Moghaddam

amin_hedayati2008@yahoo.com

1 Department of Chemical Engineering, College of Engineering, Central Tehran Branch, Islamic Azad University, Tehran, Iran

2 Department of Chemical Engineering, Sahand University of Technology, Tabriz, Iran

3 Department of Chemical Engineering, Ferdowsi University of Mashhad, Mashhad, Iran

4 Department of Chemical and Petroleum Engineering, Sharif University of Technology, Tehran, Iran index $\left(R^{2}\right)$ of 0.9752 and mean square error (MSE) of 0.0072 where defuzzification operator was center of rotation (centroid). Similarly, the maximum $R^{2}$ for rejection factor was 0.9711 where the defuzzification operator was mean of maxima (mom).

Keywords Starch · Membrane · FIS · Permeate flux · Rejection factor

\begin{tabular}{ll}
\multicolumn{2}{l}{ List of symbols } \\
V & Valve \\
ST & Storage tank \\
PL & Pipeline \\
CP & Centrifugal pump \\
HE & Heat exchanger \\
FM & Flow meter \\
B & Barometer \\
TMP & Trans membrane pressure \\
$T$ & Temperature \\
$F$ & Flow rate \\
$C$ & Concentration \\
RSM & Response surface methodology \\
FIS & Fuzzy inference system \\
RMSE & Root mean square error \\
$R^{2}$ & Correlation coefficient index \\
PF & Permeate flux \\
RF & Rejection factor \\
Mom & Mean of maxima \\
Centroid & Center of rotation \\
Probor & Probabilistic \\
Prod & Product \\
Som & Self-organization map \\
$\alpha$ & Specific cake resistance \\
$R_{\mathrm{c}}$ & Cake resistance
\end{tabular}




\section{Introduction}

Starch production plants produce high strength wastewater. Several planted crops such as corn, potato, tapioca, wheat, etc. are used to extract starch. Starch wastewater properties vary according to the type of feed stocks, extraction method, level of technology, and the purity of products. The type of feed stocks and wastewater properties of several starch factories are presented in Table 1. As it is shown, high chemical oxygen demand (COD), high biochemical oxygen demand (BOD), high solid contents, and acidic $\mathrm{pH}$ are the common characteristics of starchy wastewaters.

It is important to note that according to Tehran Province Water and Wastewater organization (TPWW), the maximum allowable COD of wastewater that is allowed to directly discharge into the surface waters is $60 \mathrm{mg} \mathrm{L}^{-1}$.

The technologies that are used in starch wastewater treatment plants are classified into three categories: (1) biological, (2) physical, and (3) chemical methods.

Colin et al. (2007) have studied the treatment of cassava starch wastewater using anaerobic horizontal flow filter. At steady state conditions and maximum organic loading rate (11.8 $\mathrm{g} \mathrm{COD} \mathrm{L}^{-1} \mathrm{~d}^{-1}$ ), $87 \%$ of the inlet COD was removed. Rajbhandari and Annachhatre (2004) assessed the possibility of an anaerobic pond system for treatment of starchy wastewater. Wastewater was treated in a series of anaerobic ponds with a total area of 7.39 ha followed by facultative ponds with an area of 29.11 ha. Overall COD and TSS removal of $90 \%$ was observed. Movahedyan et al. (2007) treated the starchy wastewater using an anaerobic baffled reactor. In optimum conditions, the COD removal of $67 \%$ was reported. Rajasimman and Karthikeyan (2007) used a fluidized bed bioreactor with low density particles to treat high organic concentration wastewater of starch industry. At the COD of $2250 \mathrm{mg} \mathrm{L}^{-1}$ and the hydraulic retention time of $24 \mathrm{~h}$, the optimum COD removal of 93.8\% was reported. Furthermore, there are several methods using aerobic biological processes to treat starch wastewater (Pirmoradian 1997; Kian 2010).

It is worthwhile noting that during biological and chemical treatment of wastewater, the possibility of starch extraction would be eliminated. Furthermore, the efficiency of chemical treatment is low and insufficient to achieve the stringent discharge standard. So, in current study, membrane technology has been selected to improve the efficiency of starch production process and wastewater treatment.

Cancino et al. (2006) used a hydrophilic polyethersulfone membrane to treat a corn starch wastewater. First, they treated the wastewater using a microfiltration membrane with a pore size of $0.2 \mu \mathrm{m}$ at a trans-membrane pressure (TMP) of $250 \mathrm{kPa}$. Permeate contained only $17 \%$ of the original wastewater $\mathrm{BOD}_{5}$. In second step, they used a reverse osmosis module for further treatment of wastewater. The permeate had only $0.2 \%$ of the original wastewater $\mathrm{BOD}_{5}$. In another study, Mannan et al. (2007) investigated the possibilities of recycling the concentrated retentate back to production line by using $\mathrm{MF}$ and $\mathrm{RO}$ membranes. Permeate flux above $100 \mathrm{~L} \mathrm{~m}^{-2} \mathrm{~h}^{-1}$ was achieved for the $100 \mathrm{~nm}$ membrane. The reported COD and $\mathrm{BOD}_{5}$ removal percentages were approximately $60 \%$.

There are several methods for wheat starch production. In Fig. 1, the block process diagram of wheat starch production (Dough-Batter process) is shown.

In hydro cyclone (Dough-Batter) process, two types of starch are produced (type A and type B). The distinctive difference between these two types of starch is the degree of polymerization. The granule size of starch type A is larger than the other one.

Table 1 Different starch wastewater characteristics

\begin{tabular}{|c|c|c|c|c|c|c|c|c|}
\hline References & $\mathrm{pH}$ & $\mathrm{COD}(\mathrm{mg} / \mathrm{L})$ & $\mathrm{BOD}(\mathrm{mg} / \mathrm{L})$ & $\begin{array}{l}\text { Total } \\
\text { solids }(\mathrm{mg} / \mathrm{L})\end{array}$ & $\begin{array}{l}\text { Volatile } \\
\text { solids }(\mathrm{mg} / \mathrm{L})\end{array}$ & $\begin{array}{l}\text { Total } \\
\text { dissolved } \\
\text { solids (mg/L) }\end{array}$ & $\begin{array}{l}\text { Total } \\
\text { suspended } \\
\text { solids }(\mathrm{mg} / \mathrm{L})\end{array}$ & $\begin{array}{l}\text { Volatile } \\
\text { suspended } \\
\text { solids (mg/L) }\end{array}$ \\
\hline $\begin{array}{l}\text { Rajasimman and } \\
\text { Karthikeyan (2007) }\end{array}$ & $4.5-4.8$ & $8560-8910$ & $5810-6020$ & $7275-7815$ & $5000-5230$ & $6035-6120$ & $1240-1695$ & $900-1005$ \\
\hline $\begin{array}{l}\text { Rajbhandari and } \\
\text { Annachhatre (2004) }\end{array}$ & $3.8-4.6$ & $13,582-14,300$ & $12,277-13,275$ & - & - & - & $6063-12,197$ & - \\
\hline Colin et al. (2007) & $3.6-6.5$ & $4200-7000$ & $1100-3900$ & $2300-6600$ & - & - & $700-2200$ & $600-2050$ \\
\hline Movahedyan et al. (2007) & $3.5-4.2$ & $16,200-26,500$ & - & - & - & - & $9440-11,940$ & $8930-11,100$ \\
\hline Yanagi et al. (1994) & $3.7-4.5$ & $15,200-20,800$ & $10,700-14,300$ & - & - & - & $1700-5300$ & - \\
\hline $\begin{array}{l}\text { Annachhatre and } \\
\text { Amatya (2000) }\end{array}$ & $3.8-4.5$ & $13,500-25,000$ & - & - & - & $6000-8000$ & $2200-4000$ & - \\
\hline
\end{tabular}


Fig. 1 Block flow diagram of hydro cyclone production process (Dough-Batter)

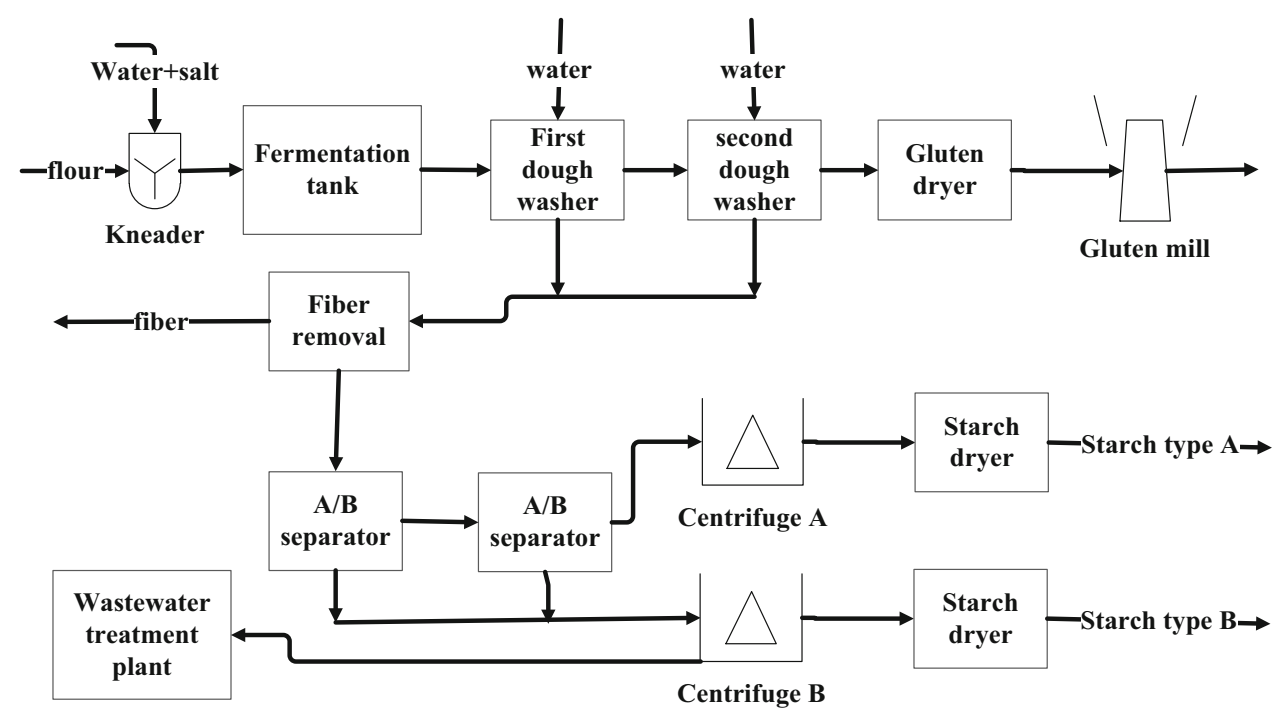

First, dough, water, and salt are mixed for $2 \mathrm{~h}$. Dough/ gluten hydration process takes place in a hydration tank. Then, through using dough washer, gluten is separated from starch solution, dried, grinded and prepared for sale. The resulted solution contains two types of starch (A and B). Starch type A and $\mathrm{B}$ are separated using centrifuge device and dried.

As illustrated in Fig. 1, a large portion of wastewater originates from centrifuging the solution of starch type B. In other words, centrifuge device is not capable of separation of the starch type B from the solution completely and some of the starch would be existed in the stream discharged to wastewater treatment plant (Pirmoradian 1997; BeMiller and Whistler 2009).

Cleaner production is not necessarily using expensive tools to reduce the contamination of industries. Cleaner production also means applying simple tools and making innovative methods to improve conventional systems, which would result in less contamination (Sans et al. 1998). There are a few researches (Bujak 2009; Dakwala et al. 2009; Virunanon et al. 2012) that investigated the improvements in starch production systems to achieve cleaner production.

There are some theoretical approaches to predict the performance of membrane process. These approaches are based on some models such as mass transfer model (Bhattacharjee and Datta 1997; Lin and Juang 2001), gel-polarization model (Palacios et al. 2002), osmotic pressure model (Wijmans et al. 1984; Ghose et al. 2000), Brownian diffusion model (Samuelsson et al. 1997), and shear-induced diffusion model (Kromkamp et al. 2002; Vincent Vela et al. 2007). The complexity of these mathematical models and their nonuniversality would limit their application.

To face this issue, several works were fulfilled to investigate the applicability of intelligent systems to simulate membrane processes. These methods would be classified as artificial neural networks (ANNs) (Bowen et al.
1998; Farshad et al. 2011; Chen and Kim 2006), adaptive neuro-fuzzy inference systems (ANFISs) (Shahsavand and Chenar 2007; Rahmanian et al. 2012), and fuzzy inference systems (FISs) (Sargolzaei et al. 2008; Altunkaynak and Chellam 2010). Accordingly, these methods that are based on the direct analysis of obtained data could simulate the membrane processes. Also, they have the ability to determine the unpredictable relations between input and output variables in many processes, which are complicated (Raasimman et al. 2010).

In general, the main preference of the systems such as FIS over other methods is that the desired predictions can be performed in an easy, fast, and accurate way which is not achievable using other forecasting tools.

In this study, a hydrophilic polyethersulfone membrane fixed in a plate and frame module was applied to modify hydro cyclone (Dough-Batter) process. The aim of this modification is to (1) improve the efficiency of starch production line and (2) decrease the organic loading rate and COD discharged into wastewater treatment system or environment. Also, FIS was applied to model non-linearity of this system. Several operators (implication, aggregation, and defuzzification) were applied and their abilities to model the permeate flux and rejection factor values were examined and the best structures for each output were selected. Finally, a comparison has been made between actual values and data obtained by FIS.

\section{Methods and materials}

\section{Membrane properties}

Hydrophilic polyethersulfone membrane (GE company,USA) with pore size of $0.65 \mu \mathrm{m}$, minimum bubble point 
of 19 psi, typical flow rate of $100.875 \mathrm{~mL} \mathrm{~min}^{-1} \mathrm{~cm}^{-2}$, operating $\mathrm{pH} 1-14$, membrane thickness $110-150 \mu \mathrm{m}$, and maximum operating temperature of $130{ }^{\circ} \mathrm{C}$ was used. The membrane area was $49 \mathrm{~cm}^{2}(7 \times 7 \mathrm{~cm})$. The plate and frame membrane module was made of steel.

\section{Modifying the process}

The process flow diagram of the modified process is shown in Fig. 2. The outlet stream from the centrifuge B that previously was discharged into wastewater treatment plant, in this way, is forwarded to a storage tank (ST). To prevent the starch settling in the tank, a mixer is also installed. Using a pipeline (PL-1), the feed stream containing low concentration of starch, leaves the tank and passes through a valve $(\mathrm{V}-1)$ and enters into the centrifugal pump (CP) with the maximum head of $50 \mathrm{~m}$ and maximum flow rate of $50 \mathrm{~L} \mathrm{~min}^{-1}$. In this study, several values of flow rates must be investigated; so the feed is divided into two streams. One is recycled to the storage tank (PL-4), and the other stream enters the heat exchanger (HE), after passing from a valve (V-2). The flow rate is regulated by valves $\mathrm{V}-2$ and $\mathrm{V}-3$. The effect of temperature on starch separation could be important due to affecting coagulation phenomena; so the temperature variations should be studied. To achieve the appropriate temperature interval, a heat exchanger (HE) which is mentioned earlier was used. As it is shown, the feed with the adjusted temperature passes through a flow meter (FM) with a maximum flow rate of $20 \mathrm{~L} \mathrm{~min}^{-1}$ and a valve (V-4) to enter into the plate and frame membrane module.

To measure and adjust the operative pressure, two manometers are installed on the feed stream (B-1) and the retentate stream (B-2). The operative pressure is adjusted using valves V-4 (inlet pressure) and V-5 (outlet pressure). TMP is calculated using the following equation:

$\mathrm{TMP}=\frac{p_{\mathrm{i}}+p_{\mathrm{o}}}{2}-p_{\mathrm{p}}$

where $p_{\mathrm{i}}$ and $p_{\mathrm{o}}$ are inlet and outlet pressure, respectively, and $p_{\mathrm{p}}$ is the pressure of permeate side.

The permeate flow leaves the membrane module through the valve $(\mathrm{V}-6)$. A portion of the retentate stream is recycled to the feed tank, and the left would be recycled to the centrifuge B for re-extracting the starch type B. It is worthwhile considering that the ratio of these two streams is adjusted by valve $\mathrm{V}-5$.

The performance of membrane filtration was evaluated by two variables; permeate flux and rejection factor. The permeate flux was defined as follows:

$J_{\mathrm{p}}=\frac{V}{A \times t}$,

where $J_{\mathrm{p}}$ is the permeate flux $\left(\mathrm{L} \mathrm{m}^{-2} \min ^{-1}\right), V$ is the permeate volume $\left(\mathrm{m}^{3}\right)$ that has been collected during time $t$ ( $\min )$, and $A$ is the active area of membrane. The rejection factor was defined as follows:

$R=1-\frac{\mathrm{COD}_{\mathrm{p}}}{\mathrm{COD}_{\mathrm{f}}}$

where $\mathrm{COD}_{\mathrm{p}}$ and $\mathrm{COD}_{\mathrm{f}}$ are the value of COD in permeate and feed streams, respectively. Influent and effluent COD were measured by standard methods (APHA 1998). Fouling could limit using membrane technology, strongly. In other works of these authors, the procedure of flux retrieving, type of backwashing, etc. for starch wastewater treatment using membrane filtration have been discussed in details (Moghaddam et al. 2013a, b, 2016).
Fig. 2 Process flow diagram of modified process

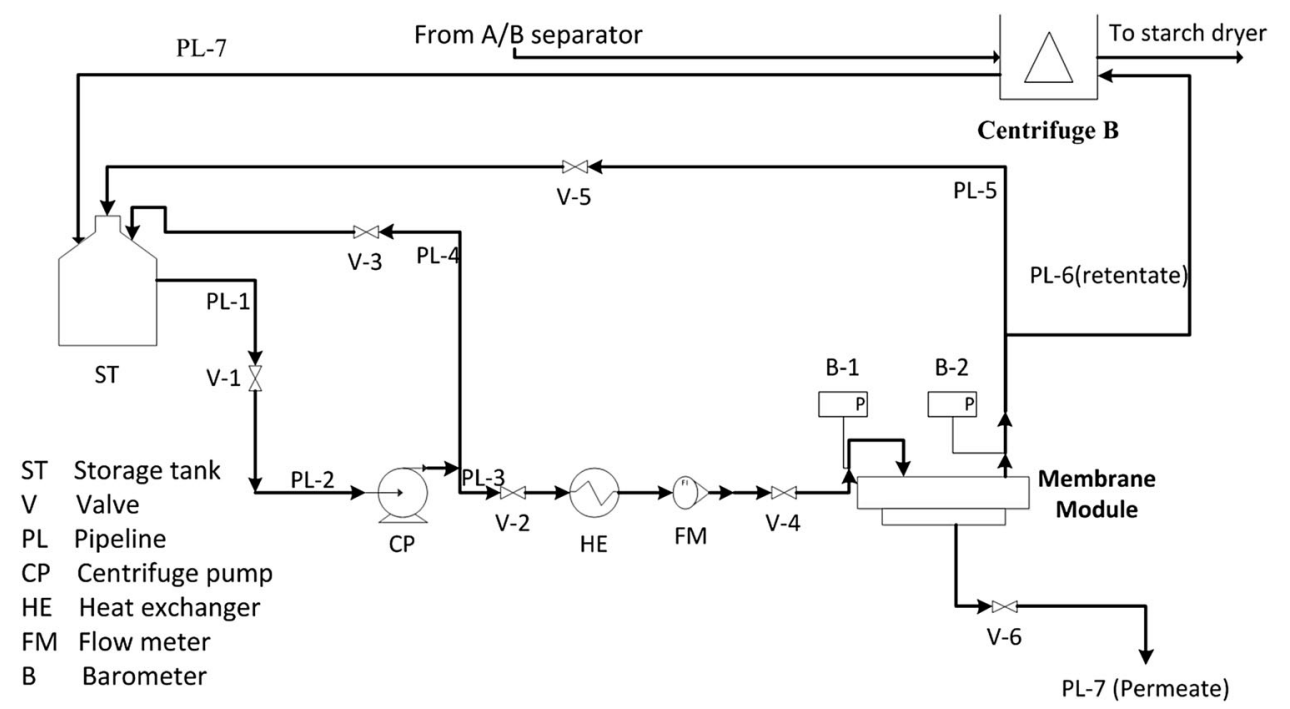




\section{Fuzzy inference system}

Fuzzy inference systems (FISs) have the ability to figure out unpredictable relations between input and output variables in many processes, which are too complicated to model by other techniques. Many investigations have been carried out in using FIS to model the membrane processes and wastewater treatment (Sadrzadeh et al. 2009). Modeling and simulation by FIS consist of two steps: (1) determining the input-output space partition and the number of rules that have to be used by the fuzzy system, and (2) finding the optimum value of the parameters that were involved in the fuzzy system (Lin and Ho 2005). The fuzzy rules that are used in fuzzy set theory are very close to human language. Therefore, this property would make the explanation and justification of the predictions easier (Rahmanian et al. 2011).

Figure 3 shows a FIS, which consists of fuzzifier, defuzzifier, and fuzzy inference engine. In Fig. $3 X$ and $Y$ are input and output data sets, respectively. A fuzzy set is characterized by a membership function $\mu_{\mathrm{f}} \varepsilon[0,1]$, which determines a grade of membership for each element within the fuzzy set (Freissinet et al. 1999).

The two most important types of fuzzy inference method are Mamdani's fuzzy inference method, which is used to predict the permeate flux and rejection factor, and so called Sugeno or Takagi Sugeno-Kang method (Yaqiong et al. 2011).

In the Mamdani fuzzy model, the "if-then" rules take the place of the usual set of equations used to characterize a system. The general "if-then" rule structure of the Mamdani algorithm is given in the following form (Rahmanian et al. 2011):

If $X$ is $A_{i}$ and $Y$ is $B_{i}$ and $\ldots$ then $Z$ is $C_{i}$ and...

$i=1,2, \ldots, n$ where $X$ and $Y$ are input variables and $Z$ is the output.

The first step is to fuzzify the input variables. The fuzzifier maps the input data $X$ into the fuzzy set $A, Y$ into the fuzzy set $B$, and so on. The next step is to evaluate the truth value for the premise of each rule, and then applying the result to the conclusion part of each rule using the fuzzy implication. The membership functions defined on the

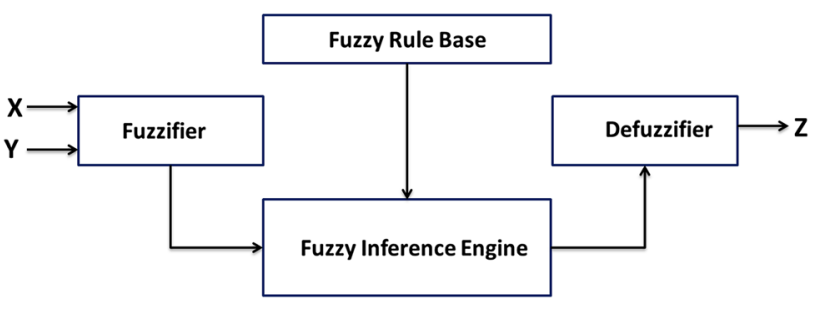

Fig. 3 Fuzzy expert system approach input variables are applied to their actual values to determine the degree of truth for each rule premise. MATLAB software R2010a (7.10.0.499) was used to construct and simulate the membrane performance.

\section{Design experiment}

The operative parameters that affect the performance of the membrane process are TMP, flow rate, temperature, $\mathrm{pH}$, and feed concentration. It was found that TMP has no considerable influence on rejection factor but improves the value of permeate flux (Sargolzaei et al. 2008). So, during conducting the experiments, the value of TMP was set at possible maximum value of 2.5 bar. The experiments layout that was adjusted by response surface methodology (RSM) and output variables, have been shown in Table 2. Sometimes, there are variables, out of control, that would affect the result of experiment. In these situations, the effects of these variables (noises) would be alleviated using blocks. In Table 2, one block was introduced because no uncontrollable variable has been detected.

The experimental plan and data analyzing generation were performed using Design Expert software (Vaughn 2011). Applying RSM to arrange experimental layout resulted in a considerable decrease in the number of experiments and also the interactions between parameters were considered. In previous work (Moghaddam et al. 2013a, b), according to the results that have been shown in Table 2, two regression models for the permeate flux (PF), rejection factor $(\mathrm{RF})$, and $\mathrm{COD}$ of permeate were generated as follows:

$$
\begin{aligned}
\mathrm{PF}= & 2.22+0.54 \times F+0.028 \times T-0.20 \times \mathrm{pH} \\
& -0.15 \times C-0.04 \times F^{2}-0.0006632 \times T^{2}, \\
\mathrm{RF}= & 78.26-0.43 \times F+0.54 \times T-0.11 \times \mathrm{pH}+2.04 \\
\times & C-0.023 \times T \times \mathrm{pH}-0.029 \times T \times C, \\
\mathrm{COD}_{\mathrm{f}}= & 93912 \times C-516 \times F \times C+648 \times T \times C-132 \\
& \times \mathrm{pH} \times C+2448 \times C^{2}-27.6 \times T \times \mathrm{pH} \times C \\
& -34.8 \times T \times C^{2} .
\end{aligned}
$$

The accuracy of models was measured using correlation coefficient index $\left(R^{2}\right)$ and mean square error (MSE), which are defined as follows:

$$
\begin{aligned}
& \text { MSE }=\frac{\sum\left(y_{\text {exp. }}-y_{\text {pred. }}\right)^{2}}{N}, \\
& R^{2}=1-\frac{\sum\left(y_{\text {exp. }}-y_{\text {pred. }}\right)^{2}}{\sum\left(y_{\text {exp. }}-\bar{y}\right)^{2}} \\
& \bar{y}=\frac{\sum y_{\text {exp. }}}{N}
\end{aligned}
$$


Table 2 Design layout of experiments in one block

\begin{tabular}{|c|c|c|c|c|c|c|c|c|}
\hline $\begin{array}{l}\text { Standard } \\
\text { run no. }\end{array}$ & $\begin{array}{l}\text { Flow } \\
\left(\mathrm{L} \min ^{-1}\right)\end{array}$ & $\begin{array}{l}\text { Temp. } \\
\left({ }^{\circ} \mathrm{C}\right)\end{array}$ & $\mathrm{pH}$ & $\begin{array}{l}\text { Conc. of } \\
\text { starch }\left(\mathrm{g} \mathrm{L}^{-1}\right)\end{array}$ & $\begin{array}{l}\text { Permeate flux } \\
\left(\mathrm{L} \mathrm{m}^{-2} \min ^{-1}\right)\end{array}$ & $\begin{array}{l}\text { COD removal } \\
(\%)\end{array}$ & $\begin{array}{l}\text { COD of } \\
\text { feed (ppm) }\end{array}$ & $\begin{array}{l}\text { COD of } \\
\text { permeate }(\mathrm{ppm})\end{array}$ \\
\hline 1 & 4.00 & 26.00 & 7.50 & 1.00 & 1.75 & 86.5 & 1200 & 162 \\
\hline 2 & 9.00 & 26.00 & 7.50 & 1.00 & 1.63 & 84.8 & 1200 & 182 \\
\hline 3 & 4.00 & 54.00 & 7.50 & 1.00 & 1.77 & 95.2 & 1200 & 58 \\
\hline 4 & 9.00 & 54.00 & 7.50 & 1.00 & 0.87 & 92.3 & 1200 & 92 \\
\hline 5 & 4.00 & 26.00 & 11.00 & 1.00 & 0.97 & 84.3 & 1200 & 188 \\
\hline 6 & 9.00 & 26.00 & 11.00 & 1.00 & 1.52 & 81.3 & 1200 & 224 \\
\hline 7 & 4.00 & 54.00 & 11.00 & 1.00 & 1.71 & 91.5 & 1200 & 102 \\
\hline 8 & 9.00 & 54.00 & 11.00 & 1.00 & 1.12 & 89.2 & 1200 & 130 \\
\hline 9 & 4.00 & 26.00 & 7.50 & 5.00 & 1.05 & 92.4 & 6000 & 456 \\
\hline 10 & 9.00 & 26.00 & 7.50 & 5.00 & 0.89 & 89 & 6000 & 660 \\
\hline 11 & 4.00 & 54.00 & 7.50 & 5.00 & 1.06 & 97.5 & 6000 & 150 \\
\hline 12 & 9.00 & 54.00 & 7.50 & 5.00 & 0.36 & 97 & 6000 & 180 \\
\hline 13 & 4.00 & 26.00 & 11.00 & 5.00 & 0.62 & 89.3 & 6000 & 642 \\
\hline 14 & 9.00 & 26.00 & 11.00 & 5.00 & 1.35 & 86.6 & 6000 & 804 \\
\hline 15 & 4.00 & 54.00 & 11.00 & 5.00 & 0.97 & 90.2 & 6000 & 588 \\
\hline 16 & 9.00 & 54.00 & 11.00 & 5.00 & 2.3 & 91 & 6000 & 540 \\
\hline 17 & 2.96 & 40.00 & 9.25 & 3.00 & 0.52 & 92 & 3600 & 288 \\
\hline 18 & 10.04 & 40.00 & 9.25 & 3.00 & 2.42 & 88 & 3600 & 432 \\
\hline 19 & 6.50 & 20.20 & 9.25 & 3.00 & 0.88 & 84.3 & 3600 & 565 \\
\hline 20 & 6.50 & 59.80 & 9.25 & 3.00 & 2.2 & 96.4 & 3600 & 130 \\
\hline 21 & 6.50 & 40.00 & 6.78 & 3.00 & 1.22 & 91.5 & 3600 & 306 \\
\hline 22 & 6.50 & 40.00 & 11.72 & 3.00 & 1.73 & 88.4 & 3600 & 418 \\
\hline 23 & 6.50 & 40.00 & 9.25 & 0.17 & 1.3 & 88 & 204 & 24 \\
\hline 24 & 6.50 & 40.00 & 9.25 & 5.83 & 1.83 & 93.5 & 6996 & 455 \\
\hline 25 & 6.50 & 40.00 & 9.25 & 3.00 & 1.77 & 90.6 & 3600 & 338 \\
\hline
\end{tabular}

where $y_{\text {exp. }}$ and $y_{\text {pred. }}$ are experimental and predicted values, respectively, and $\mathrm{N}$ is the number of data.

\section{Result and discussion}

\section{Fuzzy model}

The ranges of four input variables were divided into three sections: low (L), middle (M) and high (H). In Fig. 4 the membership function of flow rate has been illustrated. The membership function of other input variables is just like flow rate. As it is shown in Fig. 5, to improve the preciseness of the model, nine membership functions were defined for permeate flux and rejection factor. For input and output parameters, Gaussian and triangle membership functions were used, respectively. Gaussian membership function is as follows: $f(x)=e^{\frac{-(x-c)^{2}}{2 \sigma^{2}}}$

where $c$ and $\sigma$ are the parameters for the determination of the shape of the curve.

Figure 6 shows the architecture of FIS that was built for modeling the permeate flux and rejection factor. To increase the model accuracy, two separate FIS were generated for permeate flux and rejection factor. In current research, both Mamdani and Sugino model were investigated and no distinctive difference was observed between the data predicted by these two models. So, only Mamdani results have been shown.

\section{Permeate flux $\left(J_{p}\right)$}

Several structures of FIS have been generated and their ability to predict the output variables was examined in terms of the decreasing values of $R^{2}$ and MSE. As is 
Fig. 4 Membership function of flow rate

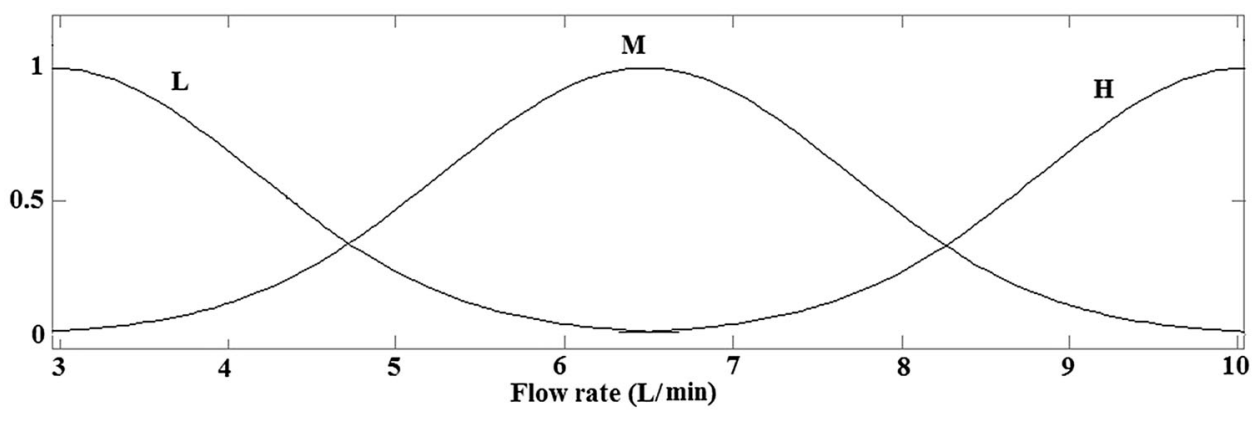

a

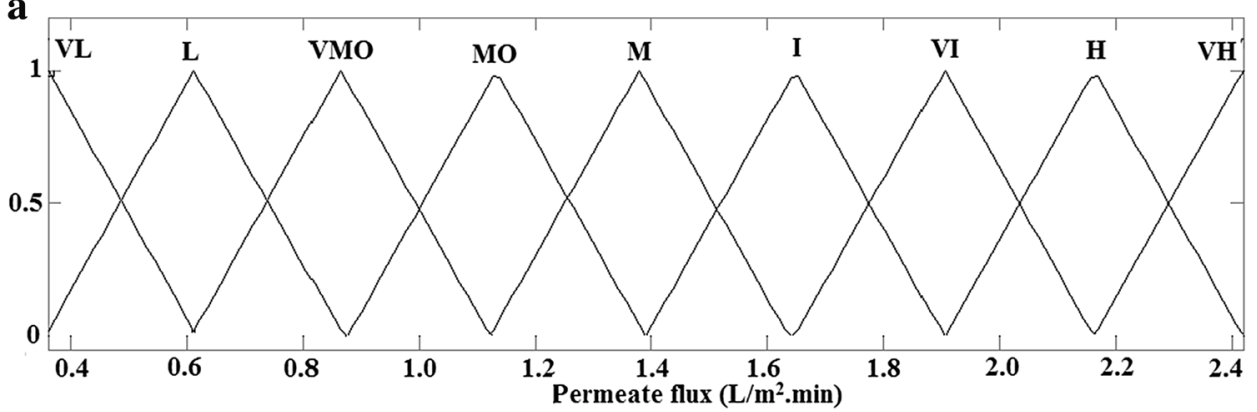

b

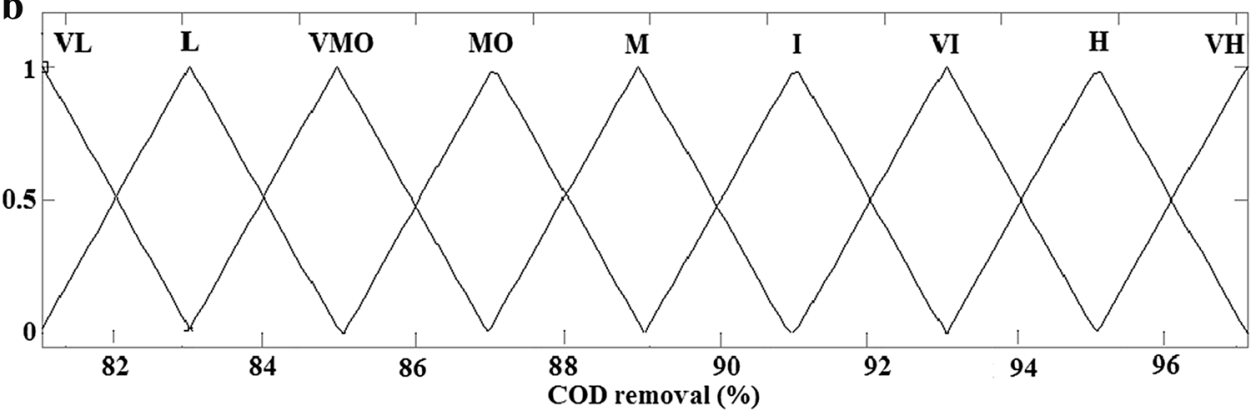

Fig. 5 a Membership function of permeate flux, $\mathbf{b}$ membership function of rejection factor $(V L$ very low, $L$ low, $V M O$ very moderate, $M O$ moderate, $M$ medium, $I$ increase, $V I$ very increase, $H$ high, $V H$ very high)

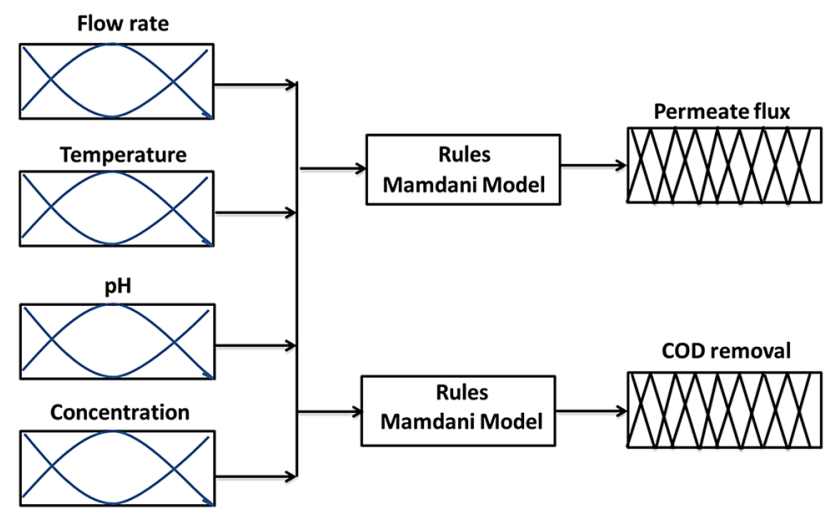

Fig. 6 The generated fuzzy inference system

presented in Table 3, the best agreement between experimental and predicted data for permeate flux is specified by $R^{2}$ of 0.9752 and MSE of 0.0072 where defuzzification operator was centroid. It is important to note that the number of rules for FIS of permeate flux is 48 . Figure 7 shows the values of residuals vs. run number for permeate flux predicted by FIS. According to Fig. 7, the maximum difference between the actual and the predicted value in this case is 0.2 . Figure 8 represents a comparison between the actual and the predicted permeate flux through a bar plot. As is shown, there is a good agreement between predicted and actual values. This agreement shows the excellent ability of this model in data predicting.

Figure 9 shows the relationship between the permeate flux and four operative parameters through surfaces generated by FIS.

It would be expected that the cake resistant would be raised after increasing the concentration, and the permeate flux would decrease. But, as it is shown in Fig. 9, the permeate flux increases with increasing concentration at $20^{\circ} \mathrm{C}$. In the following, the reason of this unusual phenomenon would be explained: 
Table 3 Comparison and selection of the best structures of FIS by Mamdani method for permeate flux

\begin{tabular}{|c|c|c|c|c|c|c|c|c|}
\hline \multirow[t]{2}{*}{ Output } & \multicolumn{5}{|c|}{ Operators } & \multicolumn{3}{|c|}{ Degree of agreement } \\
\hline & And & Or & Implication & Aggregation & Defuzzification & Average error & $R^{2}$ & MSE \\
\hline \multirow[t]{9}{*}{ Permeate flux } & Min & Max & Min & Max & Centroid & 0.0378 & 0.8242 & 0.0513 \\
\hline & Min & Max & Min & Max & Bisector & 0.0129 & 0.8781 & 0.0356 \\
\hline & Prod & Probor & Prod & Sum & Centroid & 0.0078 & 0.9752 & 0.0072 \\
\hline & Min & Max & Min & Sum & Bisector & 0.0763 & 0.6466 & 0.1031 \\
\hline & Min & Max & Min & Probor & Mom & 0.0370 & 0.8846 & 0.0337 \\
\hline & Prod & Max & Min & Sum & Mom & 0.0300 & 0.9704 & 0.0086 \\
\hline & Min & Max & Min & Max & Mom & 0.0056 & 0.9712 & 0.0084 \\
\hline & Prod & Max & Min & Sum & Som & 0.0802 & 0.9552 & 0.0131 \\
\hline & Prod & Probor & Prod & Sum & Mom & 0.0572 & 0.9422 & 0.0169 \\
\hline
\end{tabular}

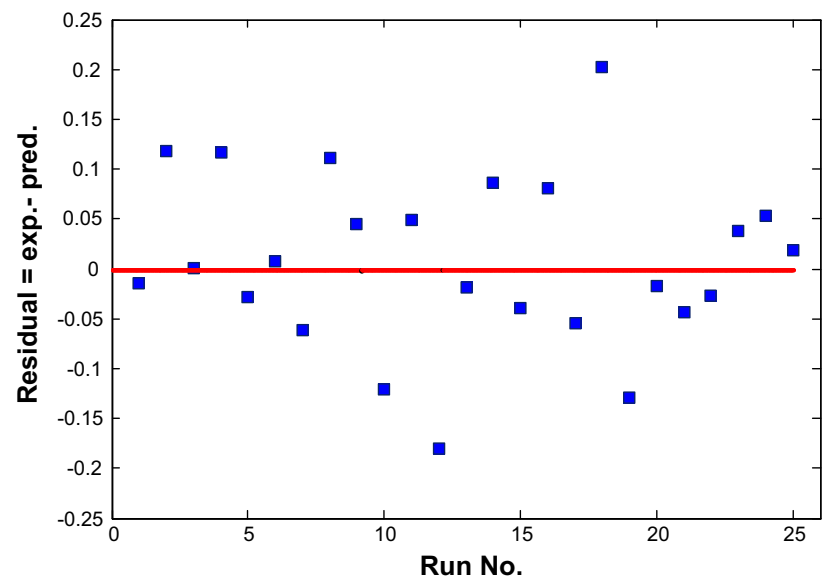

Fig. 7 Residual vs. run no. for best FIS model of permeate flux

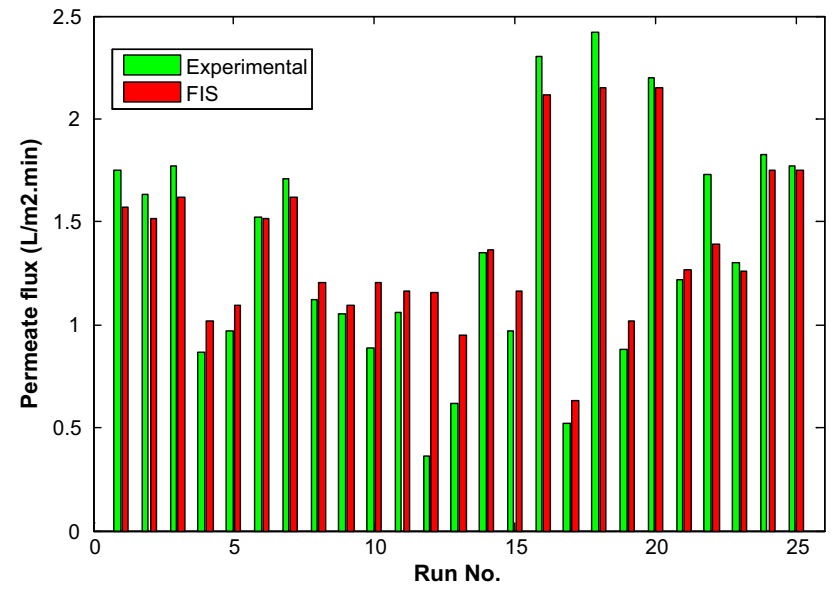

Fig. 8 Comparison between the fuzzy predicted and experimental data for the permeate flux $\left(J_{\mathrm{P}}\right)$

Specific cake resistance, $\alpha$, is defined as the cake resistance, $R_{c}$, normalized by the accumulated cake mass per unit of membrane area (Listiarini et al. 2009):
$\alpha=\frac{R_{c}}{M / A}$,

where $M$ is the mass of the cake deposited on membrane surface, and $A$ is the effective area of membrane. According to the Carman-Kozeny equation, $\alpha$ is inversely proportional to cake porosity (Chang and Kim 2005):

$\alpha=\frac{180(1-\varepsilon)}{\rho d_{\mathrm{p}}^{2} \varepsilon^{3}}$,

where $d_{\mathrm{p}}$ is the particle diameter, $\varepsilon$ is the porosity of cake layer, and $\rho$ is the particle density.

According to Eq. 12, specific cake resistance is strongly dependent on $d_{\mathrm{p}}$. So that by increasing the size of solids the cake resistant would decrease. In this case, increasing concentration at low temperature led to forming larger particles that caused decreasing cake resistant and increasing permeate flux.

\section{Rejection factor}

Similarly to permeate flux, the values of $R^{2}$ and MSE corresponded to several structures of FIS for the rejection factor have been shown in Table 4.

To check the adequacy of the final model, the predicted rejection factor vs. the actual values was checked and illustrated in Fig. 10. It is important to note that these predicted values were corresponded to the best FIS structure. In this case, the points that follow a straight line $(y=x)$ confirm that errors are normally distributed with a mean of zero. Furthermore, the $R^{2}$ of 0.9711 implies the normal distribution of predicted values versus experimental values.

In Fig. 11, four 3-D plots that show the rejection factor in terms of two operative parameters have been illustrated. 

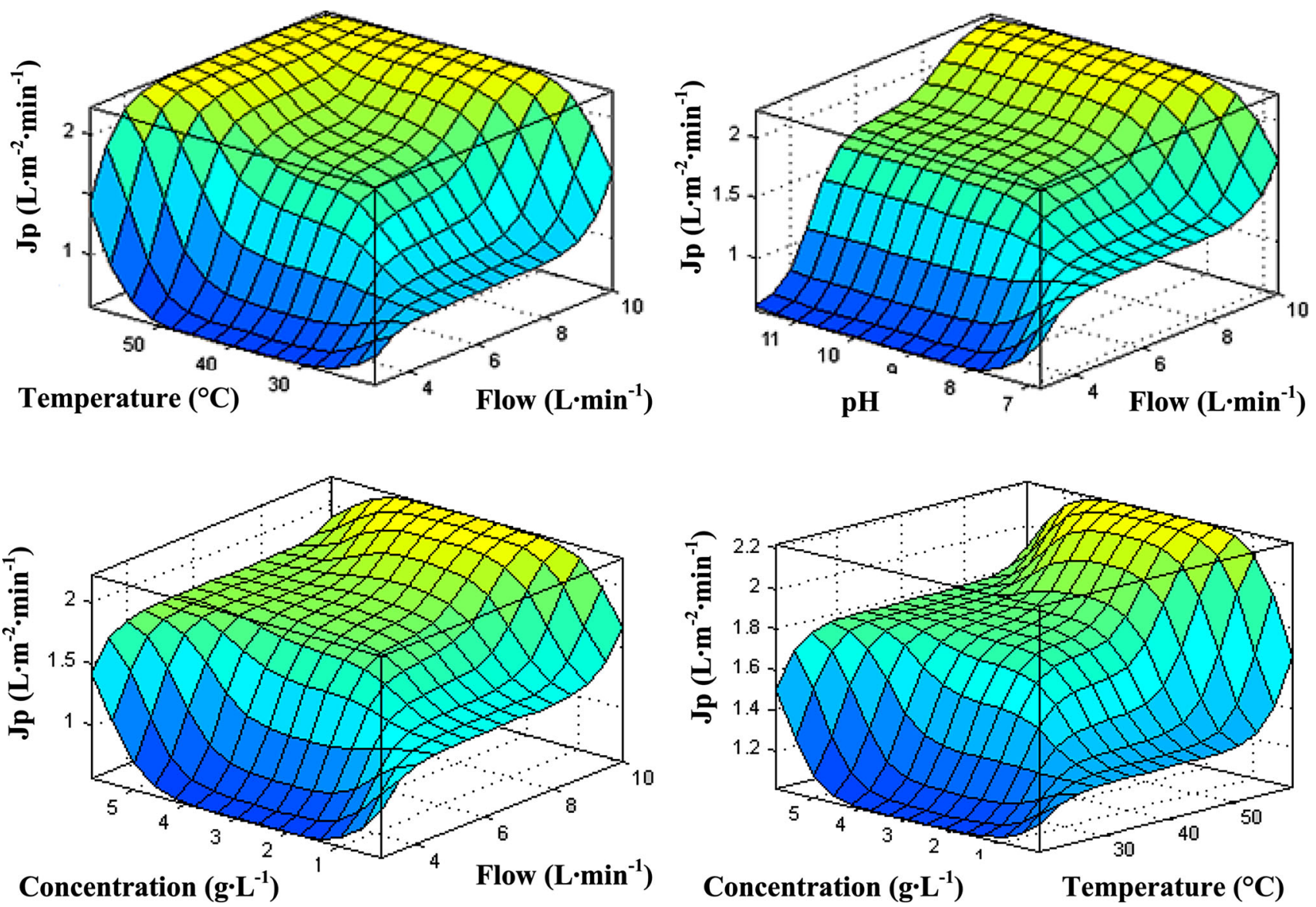

Fig. 9 FIS surfaces for permeate flux

Table 4 Comparison and selection of the best structures of FIS by Mamdani method for rejection factor

\begin{tabular}{|c|c|c|c|c|c|c|c|c|}
\hline \multirow[t]{2}{*}{ Output } & \multicolumn{5}{|c|}{ Operators } & \multicolumn{3}{|c|}{ Degree of agreement } \\
\hline & And & Or & Implication & Aggregation & Defuzzification & Average error & $R^{2}$ & MSE \\
\hline \multirow[t]{9}{*}{ COD removal } & Min & Max & Min & Max & Centroid & 0.0409 & 0.8963 & 1.7038 \\
\hline & Min & $\operatorname{Max}$ & Min & $\operatorname{Max}$ & Bisector & 0.0164 & 0.9488 & 0.8404 \\
\hline & Prod & Probor & Prod & Sum & Centroid & 0.0688 & 0.9687 & 0.5141 \\
\hline & Min & Max & Min & Sum & Bisector & 0.1002 & 0.8899 & 1.8091 \\
\hline & Min & $\operatorname{Max}$ & Min & Probor & Mom & 0.0549 & 0.9475 & 0.8626 \\
\hline & Prod & $\operatorname{Max}$ & Min & Sum & Mom & 0.0423 & 0.9711 & 0.4743 \\
\hline & Min & $\operatorname{Max}$ & Min & Max & Mom & 0.0549 & 0.9359 & 1.0533 \\
\hline & Prod & $\operatorname{Max}$ & Min & Sum & Som & 0.3728 & 0.9516 & 0.7954 \\
\hline & Prod & Probor & Prod & Sum & Mom & 0.0164 & 0.9363 & 1.0470 \\
\hline
\end{tabular}

As is shown, in middle range, change in temperature has no considerable effect on rejection factor and the rejection factor remains relatively constant. But at temperature below $30{ }^{\circ} \mathrm{C}$ or higher than $50{ }^{\circ} \mathrm{C}$, considerable change in rejection factor would be seen by changing the temperature. Similar effect was observed for change in $\mathrm{pH}$ values.

\section{Amount of recovered starch}

We assume a wheat starch production plant discharges $1500 \mathrm{~m}^{3} \mathrm{~d}^{-1}\left(1041.67 \mathrm{~L} \mathrm{~min}^{-1}\right)$ of wastewater with the average COD of $7000 \mathrm{ppm}, \mathrm{pH}$ of 6 , and temperature of $30{ }^{\circ} \mathrm{C}$ to the wastewater treatment system. Starch 
Fig. 10 Predicted rejection factor by FIS vs. experimental data
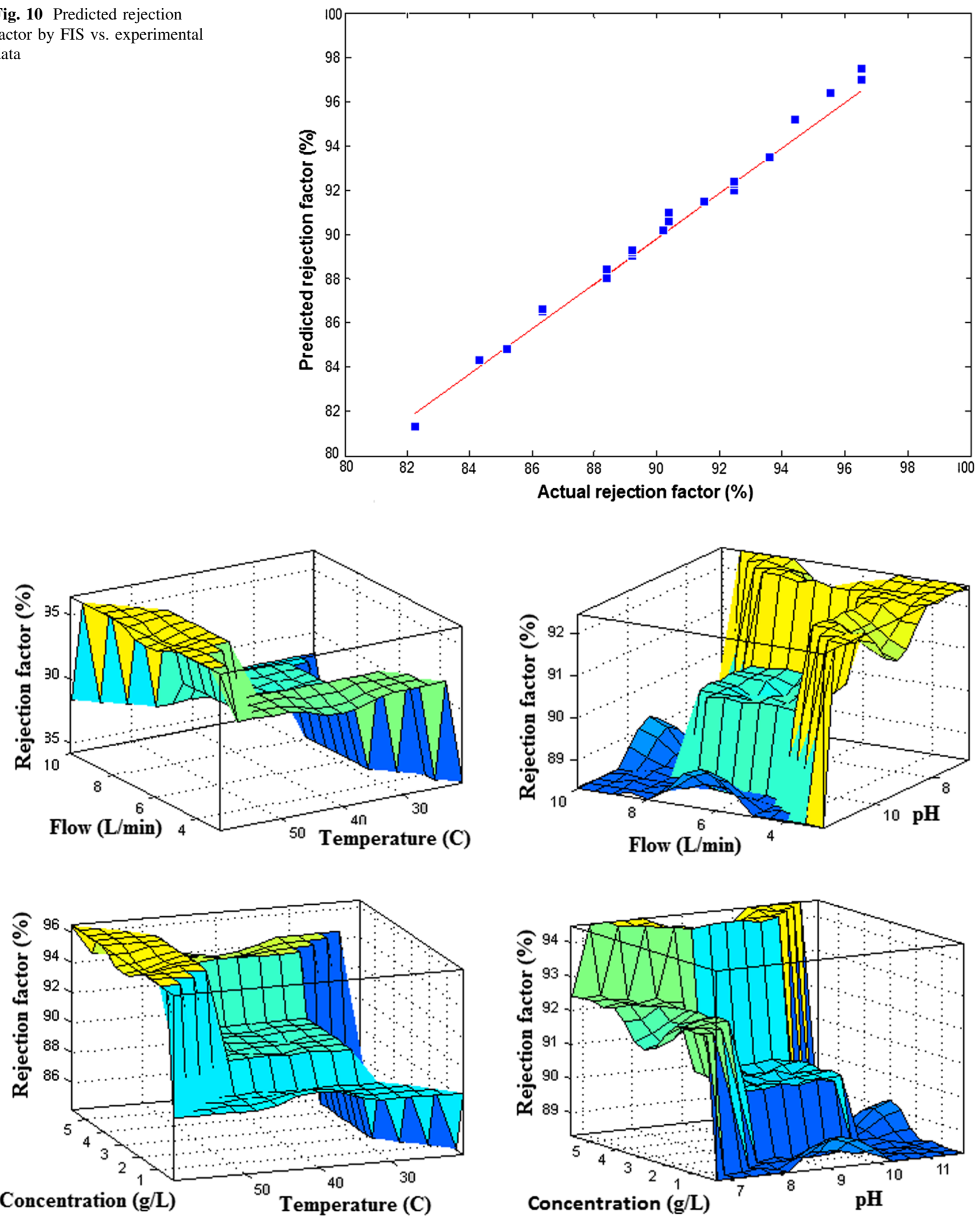

Fig. 11 FIS surfaces for rejection factor 


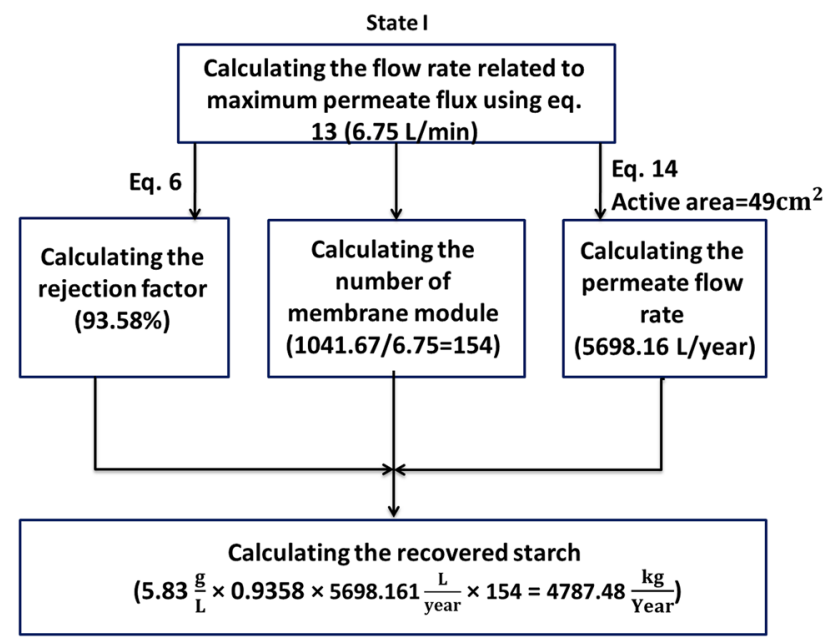

Fig. 12 The flowchart of calculating the total recovered starch for state I

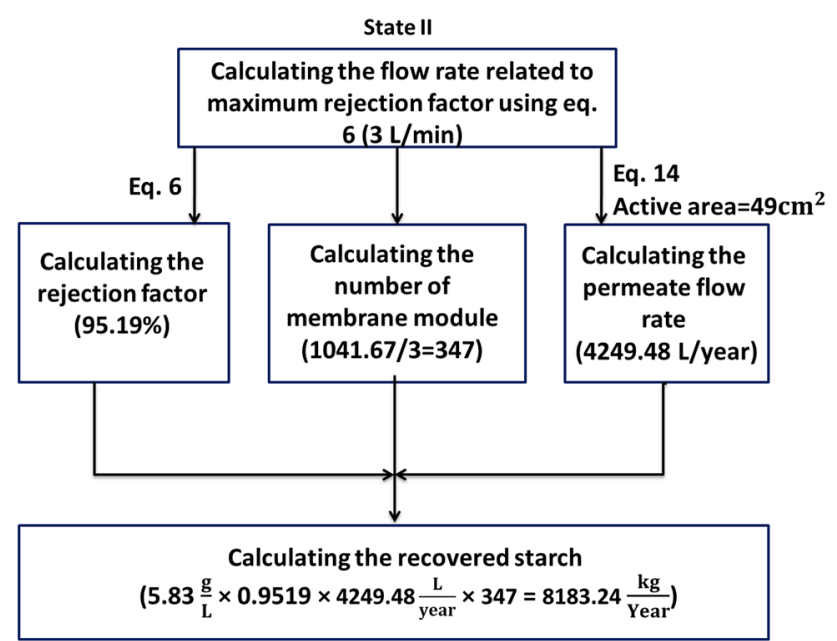

Fig. 13 The flowchart of calculating the total recovered starch for state II

concentration of $5.83 \mathrm{~g} \mathrm{~L}^{-1}$ resulted in COD value of 7000 ppm.

As it is mentioned earlier, the performance of modified system was evaluated by rejection factor and the permeate flux. So, the optimum design of system was investigated in two states. In states I and II, the aim is to obtain the maximum permeate flux and the maximum rejection factor, respectively.

\section{State I}

According to the values of $\mathrm{COD}, \mathrm{pH}$, and temperature, Eq. 5 was simplified to the following equation:
$\mathrm{PF}=0.39+0.54 \times F-0.04 \times F^{2}$.

Figure 12 shows block scheme of calculation for State I. Using Eq. 14 it is found that the maximum permeate flux would be obtained at the flow rate of $6.75 \mathrm{~L} \mathrm{~min}^{-1}$.

At this value of flow rate, according to Eq. 6, the value of rejection factor was $93.58 \%$. Consequently, $4787.48 \mathrm{~kg}$ of starch would be recovered from wastewater, annually. Additionally the COD value of wastewater decreased from 7000 to $449 \mathrm{ppm}$.

\section{State II}

According to Eq. 6, the rejection factor is maximum when the flow rate is at its minimum value. So, the flow rate was adjusted at $3 \mathrm{~L} \mathrm{~min}^{-1}$. $8183.24 \mathrm{~kg}$ of starch could be recovered each year, accordingly. Figure 13 shows the block diagram for calculating the recovered starch for state II.

The minimum and maximum values of flow rate are 3 and $10 \mathrm{~L} \mathrm{~min}^{-1}$, respectively. Wastewater flow rate is 1041.67 $\mathrm{L} \mathrm{min}^{-1}$. By selecting 347 and 104 membrane module, minimum and maximum values of flow rate for each membrane module would be achieved, respectively. Figure 14 shows the permeate flux of each membrane module (a), rejection factor (b), and total recovered starch (c) vs. number of membrane modules. Just similar to state II, the maximum starch would be recovered when the number of membrane module was at maximum value or flow rate was at minimum value. In Table 5, the amount of water and energy saving achieved by modified system have been shown.

\section{Conclusion}

In this study, a hydrophilic polyethersulfone membrane was applied for recovering the starch and recycling it into the production line. The maximum permeate flux and rejection factor were observed to be $2.42 \mathrm{~L} \mathrm{~m}^{-2} \mathrm{~min}^{-1}$ and $97.5 \%$, respectively, that were acceptable. Also, the capabilities of several structures of fuzzy inference system (FIS) for simulating the membrane filtration of starch were investigated and compared with each other. The best correlation coefficient index $\left(R^{2}\right)$ and mean square error (MSE) for predicted permeate flux were 0.9704 and 0.0086 , respectively. Similarly, $R^{2}$ and MSE for predicted rejection factor were 0.9711 and 0.4743 , respectively. According to the regression models that were obtained by response surface methodology (RSM), the recovered starch 
a

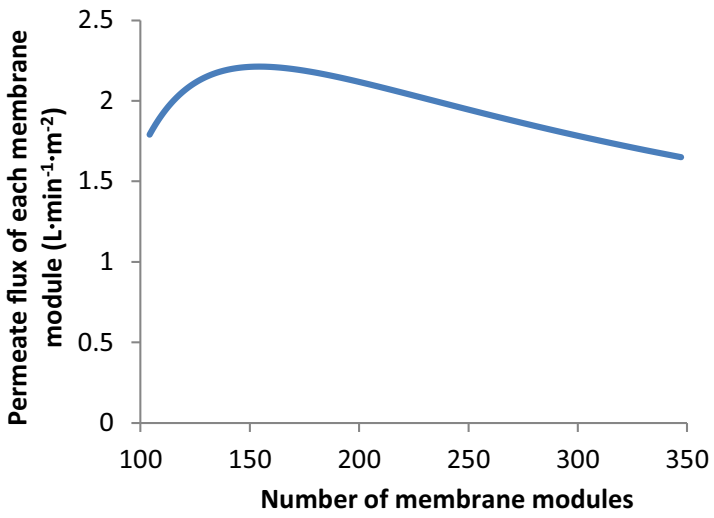

b

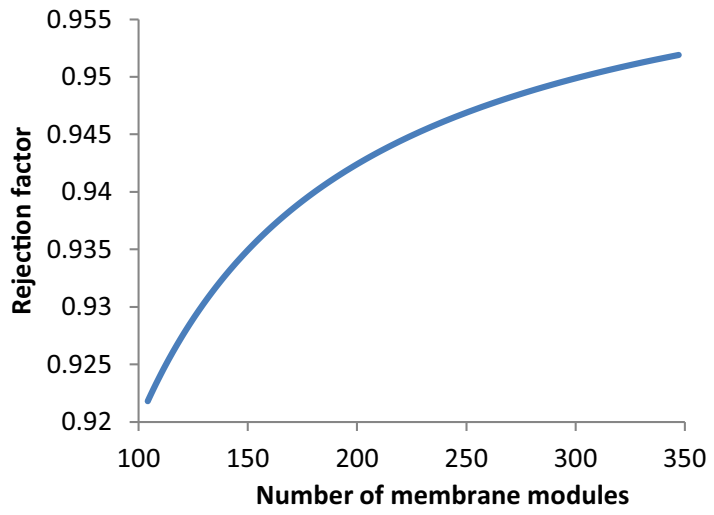

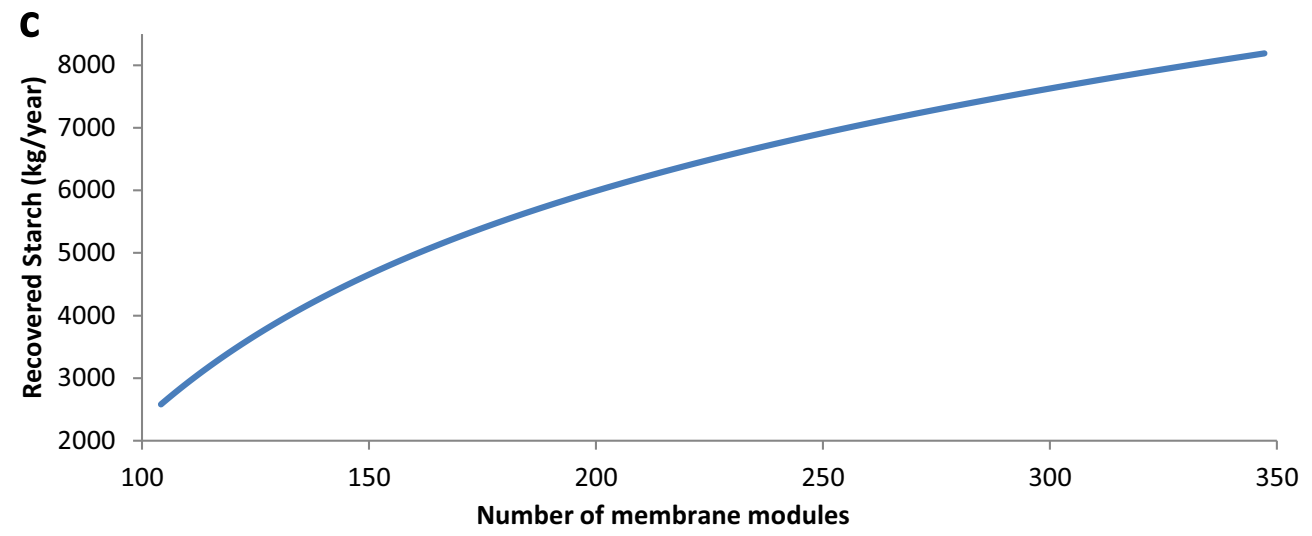

Fig. 14 a The permeate flux of one membrane module, $\mathbf{b}$ rejection factor, and $\mathbf{c}$ total recovered starch vs. number of membrane modules

Table 5 The advantages of modified system

\begin{tabular}{lllll}
\hline State & $\begin{array}{l}\text { Recovered } \\
\text { starch (ton/ } \\
\text { year) }\end{array}$ & $\begin{array}{l}\text { saved water } \\
\left(\mathrm{m}^{3} / \text { year) }\right.\end{array}$ & $\begin{array}{l}\text { Saved fuel } \\
\text { oil (GJ/year) }\end{array}$ & $\begin{array}{l}\text { Saved } \\
\text { electricity (GJ/ } \\
\text { year) }\end{array}$ \\
\hline I & 4.788 & $32.08-140.29$ & $4.69-7.79$ & $2.27-3.56$ \\
II & 8.183 & $54.83-239.77$ & $8.02-13.31$ & $3.88-6.08$ \\
\hline
\end{tabular}

under different conditions has been calculated. The maximum recovered starch was $8183.24 \mathrm{~kg} \mathrm{year}^{-1}$, which caused a huge amount of energy and water saving.

Open Access This article is distributed under the terms of the Creative Commons Attribution 4.0 International License (http:// creativecommons.org/licenses/by/4.0/), which permits unrestricted use, distribution, and reproduction in any medium, provided you give appropriate credit to the original author(s) and the source, provide a link to the Creative Commons license, and indicate if changes were made.

\section{References}

Altunkaynak A, Chellam S (2010) Prediction of specific permeate flux during crossflow microfiltration of polydispersed colloidal suspensions by fuzzy logic models. Desalination 253:188-194
Annachhatre AP, Amatya PL (2000) UASB treatment of tapioca starch wastewater. J Environ Eng 126:1149-1152

APHA (1998) Standard methods for the examination of water and wastewater, 20th edn. American Public Health Associ-ation, Washington DC

BeMiller JN, Whistler RL (2009) Starch: chemistry and technology, 3rd edn. Academic, New York

Bhattacharjee C, Datta S (1997) A mass transfer model for the prediction of rejection and flux during ultrafiltration of PEG6000. J Membr Sci 125:303-310

Bowen WR, Jones MG, Yousef HNS (1998) Prediction of the rate of crossflow membrane ultrafiltration of colloids: a neural network approach. Chem Eng Sci 53:3793-3802

Bujak J (2009) Minimizing energy losses in steam systems for potato starch production. J. Cleaner Prod. 17:1453-1464

Cancino B, Rossier B, Orellana C (2006) Corn starch wastewater treatment with membrane technologies: pilot test. Desalination 200:750-751

Chang IS, Kim SN (2005) Wastewater treatment using membrane filtration-effect of biosolids concentration on cake resistance. Process Biochem 40:1307-1314

Chen H, Kim AS (2006) Prediction of permeate flux decline in crossflow membrane filtration of colloidal suspension: a radial basis function neural network approach. Desalination 192:415-428

Colin X, Farinet JL, Rojas O, Alazard D (2007) Anaerobic treatment of cassava starch extraction wastewater using a horizontal flow filter with bamboo as support. Bioresour Technol 98:1602-1607

Dakwala M, Mohanty B, Bhargava R (2009) A process integration approach to industrial water conservation: a case study for an Indian starch industry. J Clean Prod 17:1654-1662 
Farshad F, Iravaninia M, Kasiri N, Mohammadi T, Ivakpour J (2011) Separation of toluene $/ n$-heptane mixtures experimental, modeling and optimization. Chem Eng J 173:11-18

Freissinet C, Vauclin M, Erlich M (1999) Comparison of first-order analysis and fuzzy set approach for the evaluation of imprecision in a pesticide groundwater pollution screening model. J Contam Hydrol 37:21-43

Ghose S, Bhattacharjee C, Datta S (2000) Simulation of unstirred batch ultrafiltration process based on a reversible pore-plugging model. J Membr Sci 169:29-38

Kian M (2010) Investigation and comparison of conventional activated sludge and membrane bioreactor to treat starchy wastewater. Sharif University of Technology

Kromkamp J, Van Domselaar M, Schroèn K, Van Der Sman R, Boom R (2002) Shear-induced diffusion model for microfiltration of polydisperse suspensions. Desalination 146:63-68

Lin CJ, Ho WH (2005) An asymmetry-similarity-measure-based neural fuzzy inference system. Fuzzy Sets Syst 152:535-551

Lin SH, Juang RS (2001) Mass-transfer in hollow-fiber modules for extraction and back-extraction of copper (II) with LIX64 N carriers. J Membr Sci 188:251-262

Listiarini K, Sun D, Leckie J (2009) Organic fouling of nanofiltration membranes: evaluating the effects of humic acid, calcium, alum coagulant and their combinations on the specific cake resistance. J Membr Sci 332:56-62

Mannan S, Fakhru'l-Razi A, Alam MZ (2007) Optimization of process parameters for the bioconversion of activated sludge by penicillium corylophilum, using response surface methodology. J Environ Sci 19:23-28

Moghaddam AH, Shayegan J, Sargolzaei J, Bahadori T (2013a) Response surface methodology for modeling and optimizing the treatment of synthetic starchy wastewater using hydrophilic PES membrane. Desalin Water Treat 51:37-39

Moghaddam AH, Sargolzaei J, Shayegan J, Bahadori T (2013b) Optimization of cleaning procedure for polyethersulfone (PES) membrane by a statistically designed approach. Recent Paten Chem Eng 6:107-115

Moghaddam AH, Shayegan J, Sargolzaei J (2016) Investigating and modeling the cleaning-in-place process for retrieving the membrane permeate flux: case study of hydrophilic polyethersulfone(PES). J Taiwan Inst Chem Eng 62:150-157

Movahedyan H, Assadi A, Parvaresh A (2007) Performance evaluation of an anaerobic baffled reactor treating wheat flour starch industry wastewater. Iran J Environ Health Sci Eng 4:77-84

Palacios V, Caro I, Pérez L (2002) Comparative study of crossflow microfiltration with conventional filtration of sherry wines. J Food Eng 54:95-102

Pirmoradian K (1997) Surveying the treatability of starch industry wastewater using activated sludge and chemicals. Sharif University of Technology
Raasimman M, Govindarajan I, Karthikeyan C (2010) Artificial neural network modeling of an inverse fluidized bed bioreactor. J Appl Sci Environ Manag 11:65-69

Rahmanian B, Pakizeh M, Esfandyari M, Maskooki A (2011) Fuzzy inference system for modeling of zinc removal using micellarenhanced ultrafiltration. Sep Sci Technol 46:1571-1581

Rahmanian B, Pakizeh M, SaA Mansoori et al (2012) Prediction of MEUF process performance using artificial neural networks and ANFIS approaches. J Taiwan Inst Chem Eng 43:558-565

Rajasimman M, Karthikeyan C (2007) Aerobic digestion of starch wastewater in a fluidized bed bioreactor with low density biomass support. J Hazard Mater 143:82-86

Rajbhandari B, Annachhatre A (2004) Anaerobic ponds treatment of starch wastewater: case study in Thailand. Bioresour Technol 95:135-143

Sadrzadeh M, Ghadimi A, Mohammadi T (2009) Coupling a mathematical and a fuzzy logic-based model for prediction of zinc ions separation from wastewater using electrodialysis. Chem Eng J 151:262-274

Samuelsson G, Huisman I, Trägårdh G, Paulsson M (1997) Predicting limiting flux of skim milk in crossflow microfiltration. J Membr Sci 129:277-281

Sans R, Ribo J, Alvarez D, Forne C, Puig M, Puig F (1998) Minimization of water use and wastewater contaminant load. J Clean Prod 6:365-369

Sargolzaei J, Khoshnoodi M, Saghatoleslami N, Mousavi M (2008) Fuzzy inference system to modeling of crossflow milk ultrafiltration. Appl Soft Comput 8:456-465

Shahsavand A, Chenar MP (2007) Neural networks modeling of hollow fiber membrane processes. J Membr Sci 297:59-73

Vaughn NA et al (2011) Design-Expert V. Version 8 for Windows Stat-Ease, Inc, Minneapolis

Vincent Vela MC, Álvarez Blanco S, Lora García J, GozálvezZafrilla JM, Bergantiños Rodríguez E (2007) Utilization of a shear induced diffusion model to predict permeate flux in the crossflow ultrafiltration of macromolecules. Desalination 206:61-68

Virunanon C, Ouephanit C, Burapatana V, Chulalaksananukul W (2012) Cassava pulp enzymatic hydrolysis process as a preliminary step in bio-alcohols production from waste starchy resources. J Clean Prod 39:273-279

Wijmans J, Nakao S, Smolders C (1984) Flux limitation in ultrafiltration: osmotic pressure model and gel layer model. J Membr Sci 20:115-124

Yanagi C, Sato M, Takahara Y (1994) Treatment of wheat starch waste water by a membrane combined two phase methane fermentation system. Desalination 98:161-170

Yaqiong L, Man LK, Zhang W (2011) Fuzzy theory applied in quality management of distributed manufacturing system: a literature review and classification. Eng Appl Artif Intell 24:266-277 